\title{
ESTRATÉGIAS PEDAGÓGICAS NO ENSINO DE ALGORITMOS E PROGRAMAÇÃO ASSOCIADAS AO USO DE JOGOS EDUCACIONAIS
}

\author{
Clevi Elena Rapkiewicz', Gilse Falkembach ${ }^{2}$, Louise Seixas ${ }^{2}$, Núbia dos Santos \\ Rosa $^{1}$, Vanildes Vieira da Cunha ${ }^{3}$, Miriam Klemann ${ }^{4}$ \\ ${ }^{1}$ UENF-Universidade Estadual Norte Fluminense Darcy Ribeiro, ${ }^{2}$ CINTED - UFRGS \\ ${ }^{3}$ FAETEC, ${ }^{4}$ Colégio Mauá -RS
}

clevi@uenf.br, gilsemf@terra.com.br, louise.seixas@ufrgs.br, nubrosa@gmail.com, vavic@ superig.com.br, mikle@maua.g12.br

\begin{abstract}
Resumo. $O$ conteúdo introdutório de algoritmos e programação é difícil de ser trabalhado e apresenta vários problemas que levam os alunos a abandonar a disciplina. Entre os vários motivos, está a falta de motivação dos alunos e a dificuldade dos mesmos em desenvolver o raciocínio lógico necessário para a construção dos algoritmos. Este artigo propõe o uso de estratégias pedagógicas utilizando jogos computacionais para amenizar os problemas citados, mostrando que usar recursos de informática na própria área da educação em informática pode ser interessante.
\end{abstract}

Palavras-chave: jogos, algoritmos, estratégias pedagógicas

\section{PEDAGOGICAL STRATEGIES IN THE TEACHING OF ALGORITHMS USING COMPUTATIONAL GAMES}

Abstract. It is difficult to work in classroom with the introductory content of algorithms and programming, and it poses many problems that make the students give up. The reasons for this include the lack of motivation of the students and their difficulty in developing the necessary logical reasoning for the construction of algorithms. This paper proposes the use of pedagogical strategies, such as computational games, to mitigate these problems, suggesting that the use of computational resources in the area of computer education might be interesting.

Key-words: games, algorithms, pedagogical strategies

\section{1-Introdução: o problema}

A disciplina de algoritmos é considerada a base para o ensino de programação nos cursos de Ciência da Computação. Esta disciplina aborda os princípios da lógica de programação, com o objetivo de desenvolver a capacidade de análise e resolução de problemas dos alunos através da descrição dos mesmos na forma de algoritmos. Além disso, ela faz parte do plano curricular de outros cursos, como os de engenharia, com a finalidade de introduzir os conceitos de programação. Essas disciplinas costumam ter altos índices de evasão e reprovação, sendo um dos gargalos existentes nos cursos de graduação, particularmente de computação, dificultando ou até mesmo impedindo a continuidade dos alunos no curso.

Diversos problemas podem ser citados no processo de ensino e aprendizagem de algoritmos e programação que culminam em desmotivação, reprovação ou evasão. Entre esses, mencionados por Rodrigues (2002), pode-se destacar: i) dificuldade de adaptação dos alunos desenvolverem raciocínio lógico quando estão acostumados a 
decorar o conteúdo; ii) falta de motivação do aluno gerada pelo despreparo e o desânimo quando ele acredita que a disciplina constitui um obstáculo extremamente difícil de ser superado. Além desses motivos, pode ser apontado como fator limitante o ensino instrucionista: segundo Borges (2000), o modo tradicional não consegue facilmente motivar os alunos a se interessar pela disciplina, entre outras razões, pois não é clara para os mesmos a importância de certos conteúdos para sua formação.

Outro problema importante é apontado por Pereira e Rapkiewicz (2004) e refere-se às dificuldades apresentadas por grande parte dos alunos em assimilar as abstrações envolvidas no processo de ensino e aprendizagem de programação. Além disso, muitos dos alunos não conseguem desenvolver o raciocínio lógico necessário para o posterior desenvolvimento de programas.

Dentre os problemas relacionados, o foco deste trabalho está no desenvolvimento do raciocínio lógico do aluno uma vez que este não consegue abstrair a lógica dos problemas e transformá-la numa sequiência lógica para posteriormente desenvolver o algoritmo. Como mostra Mendes (2002), a necessidade da prática em técnicas de resolução de problemas e de um bom nível de conhecimentos são fatores que dificultam a aprendizagem por parte dos alunos.

$\mathrm{O}$ uso exagerado da repetição ad infinitum de problemas com enunciados textuais (vide exemplo na Figura 1, com dois enunciados diferentes para um mesmo problema) passado numa lista de exercícios impressa ou no quadro torna o processo de ensino e aprendizagem monótono e cansativo. A partir do enunciado o professor procura trabalhar a destreza do aluno em entender o enunciado, elaborar uma solução algorítmica que deve ser descrita, na maior parte das vezes, em pseudo-código . Outras vezes, são solicitadas representações visuais na forma de fluxogramas ou diagramas de Chapin (Yourdon, 1990).

1) Desenvolva um algoritmo para colocar seis litros de água em um vaso, utilizando como instrumentos dois vasos, um com capacidade de 7 litros e outro de 5 litros.

2) Suponha dois recipientes com capacidade respectivamente para 7 e 5

litros. $\quad$ Como você faria para colocar 6 litros de um líquido qualquer em

um dos vasos tendo possibilidade de fazer as seguintes ações:

Encher o vaso a partir de uma fonte do líquido.

Figura 1: Enunciado textual de um problema típico proposto para alunos de algoritmos

Essa forma de abordar o ensino de algoritmos e programação não contribui muito para motivar os alunos, dado que adia o contato dos alunos com o uso de um recurso prático (o computador) que é a própria razão do desenvolvimento de algoritmos e programas. Pode-se afirmar que é ingenuidade esperar que os adolescentes na faixa de 16 a 18 anos que adentram na universidade, numa geração que já vem com familiaridade significativa com o uso de computador e Internet, tenham interesse em passar horas e horas desenvolvendo soluções no papel ou quadro sem poder testá-las.

Outro problema é quanto à verificação da efetividade do algoritmo, isto é, verificar se o mesmo faz o que deveria fazer (ver se funciona). Essa parte da disciplina costuma ser trabalhada com o aluno fazendo teste de mesa ou chinês, sobre o algoritmo desenvolvido por ele ou sobre outros trazidos prontos para a sala de aula pelo professor. Ou seja, o aluno deve seguir passo a passo o algoritmo e ir executando as ações para 
verificar a funcionalidade da solução proposta. Além de ser desmotivante, essa abordagem introduz nova fonte de problemas, pois o aluno enfrenta dificuldades no próprio ato de acompanhar o passo a passo.

Analisando estas questões sob a ótica de uma pedagogia que encara a aprendizagem como um processo de construção de conhecimento, é possível identificar e intervir, por meio de estratégias adequadas, em diferentes etapas deste processo.

Tomando por base a teoria de Jean Piaget (1983), em sua obra Epistemologia Genética o autor destaca o papel fundamental da ação do sujeito sobre o objeto, abstraindo informações, pois este objeto reage à ação do sujeito, e assim em sucessivas interações. Ao refletir sobre suas ações e o resultado de suas abstrações, o sujeito vai construindo relações entre elas, dotando-as de significados, o que se constitui no processo de construção do conhecimento. As primeiras ações do sujeito sobre o objeto são ações sensório-motoras, depois operatórias concretas, operatórias, lógicas e finalmente formais. Voltando ao foco pedagógico, no ensino de algoritmos como discutido anteriormente, pretende-se que o aluno apresente um raciocínio lógico-formal a partir de um enunciado, sem oferecer-lhe a possibilidade de interagir em outros níveis, anteriores e necessários para este processo.

Neste artigo propõe-se o uso de jogos numa fase introdutória do ensino de algoritmos e programação, utilizando recursos computacionais e gráficos, como recurso pedagógico orientado a minimizar as dificuldades anteriormente citadas, e promover a possibilidade do aluno construir o seu conhecimento nesta área, por meio de ações concretas, experimentações e reflexões. Procura, ainda, buscar uma forma de representação da solução de modo que todos os que estão envolvidos no processo entendam, sem utilizar uma linguagem pré-definida para tal como o pseudo-código: ao contrário, a forma de representação da solução será resultado de interações entre os participantes do grupo, que está aprendendo junto, numa abordagem colaborativa.

$\mathrm{O}$ artigo está estruturado em 5 seções. A primeira seção é a introdução ao tema do trabalho desenvolvido. A segunda seção apresenta algumas referências em relação ao uso de jogos educacionais e sua importância. Ressaltando o uso de estratégias pedagógicas adequadas, a seção 3 mostra como os jogos podem ser utilizados de forma eficiente. A quarta seção exemplifica a proposta a partir de um jogo desenvolvido no âmbito da disciplina Courseware da Especialização em Informática na Educação (ESPIE) da UFRGS. Por último, a seção 5 apresenta algumas considerações finais.

\section{2-Jogos Educacionais no ensino de programação}

Segundo Tarouco et al (2004) os jogos podem ser ferramentas eficientes, pois eles divertem enquanto motivam, facilitam o aprendizado e aumentam a capacidade de retenção do que é ensinado, exercitando as funções mentais e intelectuais do jogador. De acordo com Tarouco (2005) algumas características que fazem com que os jogos sejam atrativos são: os jogos possuem regras (fornecem uma estrutura), têm metas (produzem motivação), são interativos (permitem agir), têm resultados e realimentação (favorecem a aprendizagem) e são divertidos (tornam o processo agradável).

Os jogos não servem somente para entretenimento. Como mostra Johnson (2005) os jogos forçam o aluno a decidir, a escolher, a priorizar. Todos os benefícios intelectuais do jogo resultam dessa virtude fundamental, porque aprender como pensar, em última análise, tem a ver com aprender a tomar a decisão certa: pesar a evidência, analisar situações, consultar suas metas em longo prazo, e então, decidir.

O mesmo autor considera que as decisões são baseadas em duas modalidades de trabalho intelectual que são fundamentais ao aprendizado, colateral ao ato de jogar: 
- Sondagem - A sondagem freqüentemente toma a forma de busca pelos limites da simulação, os pontos nos quais a ilusão de realidade é fragmentada e pode-se perceber que tudo não passa de um punhado de algoritmos nos bastidores.

- Investigação Telescópia - relaciona-se com a ordem, não caos; tem a ver com construir a hierarquia adequada de tarefas e evoluir através delas na sequiência correta.

Johnson (2005) ainda compara a maneira como os jogadores pensam com a forma como os programadores pensam quando escrevem um código: uma série de instruções aninhadas com múltiplas camadas.

Podemos dizer que o algoritmo está presente implicitamente no jogo e no modo como os alunos pensam no jogo, só que o aluno ainda não consegue enxergá-lo explicitamente. Através dos jogos os alunos se sentem mais motivados no desenvolvimento das tarefas e, conseqüentemente, desenvolvem o raciocínio, sobretudo quando os jogos agregam um conjunto de elementos multimídia que prendem mais a atenção do que questões em papel ou no quadro.

Outro fator importante é o da simulação. A simulação é um benefício que o do jogo oferece, uma vez que o aluno consegue visualizar sua ação sobre o jogo. Através da simulação o aluno consegue visualizar os passos necessários para alcançar um resultado quando, por exemplo, visualiza, seleciona e transporta personagens no jogo. $\mathrm{O}$ jogo permite tornar real o que seria apenas imaginário no caso de enunciados de problemas apresentados no quadro ou em listas de exercício em papel.

As chamadas barreiras da aprendizagem, ou seja, as dificuldades na aprendizagem de Algoritmos ocorrem por falta de um método de ensino adequado para essa disciplina, de material didático inovador e de pressupostos pedagógicos que, no ensino desse conteúdo partem do abstrato para o concreto. Para a compreensão das operações realizadas pela máquina, exige-se um grande esforço cognitivo do professor para explicar e para o aluno abstrair e entender como ocorrem internamente essas operações até chegar ao resultado esperado. O ensino de Algoritmos na maioria das Instituições se dá através de aulas convencionais e essas não privilegiam o que se faz necessário para a aprendizagem desse conteúdo. São necessárias ações pedagógicas que contemplem esse processo, ou seja, são necessárias ações pedagógicas voltadas à aprendizagem para a Resolução de Problemas que permitem desenvolver capacidades como atenção, concentração, pensamento criativo e outras habilidades perceptuais psicomotoras indispensáveis para agilizar o raciocínio.

Muitos dos alunos que apresentam dificuldades no aprendizado de Algoritmos vêm acumulando essa dificuldade desde o início de sua vida escolar. Os problemas de aprendizagem, gerados nessa ocasião, se não forem sanados, repercutem na vida escolar desse aluno, refletindo-se na aprendizagem para a Resolução de Problemas.

Uma possibilidade para minimizar as dificuldades encontradas na disciplina de Algoritmos, que é baseada na Resolução de Problemas, é o uso de jogos educacionais. $\mathrm{O}$ uso de jogos de forma lúdica propicia flexibilidade e criatividade fazendo o aluno explorar, pesquisar, encorajando o pensamento criativo, ampliando o universo, saciando a curiosidade, alimentando a imaginação e estimulando a intuição, e tudo isso contribui para o aprendizado. O jogo por meio do lúdico pode ser desafiador e sempre vai gerar uma aprendizagem que se prolonga fora da sala de aula, fora da escola, pelo cotidiano e acontece de forma interessante e prazerosa.

Os jogos computacionais são softwares que apresentam conteúdo e atividades práticas com objetivos educacionais baseados no lazer e diversão. Nesses jogos a abordagem pedagógica adotada utiliza a exploração livre e o lúdico e como consequiência, estimulam o aprendiz. Os jogos digitais auxiliam na construção da 
autoconfiança e podem incrementar a motivação no contexto da aprendizagem. A atividade de jogar é uma alternativa de realização pessoal que possibilita a expressão de sentimentos, de emoção e propicia a aprendizagem de comportamentos adequados e adaptativos. Segundo Silveira, 1998:

Os jogos computadorizados são elaborados para divertir os alunos e com isto prender sua atenção o que auxilia no aprendizado de conceitos, conteúdos e habilidades embutidos nos jogos, pois, estimulam a auto-aprendizagem, a descoberta, despertam a curiosidade, incorporam a fantasia e o desafio. (p.45)

Os jogos interativos para fins educacionais vão além do entretenimento, eles servem para ensinar e educar e se constituem em ferramentas eficientes de ensino e aprendizagem. Cabe ao professor planejar, organizar e controlar as atividades de ensino utilizando os recursos tecnológicos apropriados a fim de criar as condições ideais para que os alunos dominem os conteúdos, desenvolvam a iniciativa, a curiosidade científica, a atenção, a disciplina, o interesse, a independência e a criatividade. Isso tudo contribui para estimular o raciocínio necessário para a Resolução de Problemas, o que facilita o desenvolvimento de algoritmos.

A multimídia interativa pode ajudar nesse processo possibilitando a criação de jogos, com uma prática pedagógica implícita que propiciam resultados pedagógicos importantes. Portanto, os jogos digitais podem oferecer um universo complexo de significados, centrado na ludicidade, subsidiando a construção do conhecimento do aluno conforme seu ritmo, de forma agradável, agregando entretenimento, informação e ludicidade e preparando-o para ser um resolvedor de problemas.

Os jogos com atividades para exercitar a habilidade mental e a imaginação, agradam, entretêm, prendem a atenção, entusiasmam e ensinam com maior eficiência, porque transmitem as informações de várias formas, estimulando diversos sentidos ao mesmo tempo e sem se tornar cansativo. Servem para ensinar e aprender algoritmos. Em um jogo a carga informativa pode ser significantemente maior, os apelos sensoriais podem ser multiplicados e isso faz com que o interesse do aluno seja mantido, promovendo a retenção da informação e facilitando a aprendizagem. Portanto, toda a atividade que incorporar a ludicidade pode se tornar um recurso facilitador do processo de ensino e aprendizagem em qualquer área.

O ensino de Algoritmos por meio dos jogos digitais pode promover, de forma lúdica, a formação de novas atitudes a fim de diminuir as dificuldades encontradas pelos alunos e facilitar o processo de aprendizagem.

Os recursos oferecidos pelas tecnologias digitais servem como

ferramentas para que os jogos educacionais, por meio da interação, da alegria, da magia provoquem a vontade de querer saber e de querer fazer mais. Há um envolvimento que

serve de estimulo para aprender e tentar alcançar os objetivos do jogo. É uma alternativa de realização pessoal que, além de possibilitar a expressão de sentimentos e emoções aumenta a possibilidade de êxito no aprender.

Há fortes razões, portanto (motivação, retroalimentação, tornar a aprendizagem prazerosa e concreta) para o uso de jogos educacionais no processo de ensino e aprendizagem de algoritmos e programação.

\section{3-As Estratégias Associadas aos Jogos}

É interessante analisar a tática do jogo como estratégia pedagógica no ensino e aprendizagem de algoritmos e programação uma vez que o uso de jogos computacionais 
permite atuar junto a problemas apontados na introdução, a saber: falta de motivação, falta de contato com computador, dificuldade de seguir passo a passo à solução.

Os jogos são praticados a partir de decisões em situações de conflitos e podem ter três modalidades, segundo a Teoria de Jogos (Von Neuman; Morgenstein, 1944, in Fayard, 2000, p.11): "a formal, que é puramente matemática e dedutiva e não depende de dados empíricos; a prescritiva (ou normativa), que é concernente ao cálculo da otimização das decisões e que depende da explicitação dos objetivos e das circunstâncias; e a descritiva, que pretende dar conta de como as pessoas realmente tomam decisões e depende, pois, de dados do efetivo comportamento dos atores e das situações cobertas por essa teoria".

A "Teoria dos Jogos" consiste na "codificação do pensamento estratégico" sendo, portanto, fundamental este conceito. Embora o "pensamento estratégico" receba críticas - o ato de ganhar é bem definido e facilmente discernido. Fayard (2000) enfatiza que a liberdade de ação e a perspectiva de incerteza do outro podem se tornar motivação para melhorar a situação do ator no conflito. $\mathrm{O}$ jogador visa alcançar uma meta, que é ganhar o jogo, e por conta de seus objetivos usa estratégias.

O jogar em si, porém, pode ser um mero divertimento, sem levar necessariamente ao resultado almejado pelo professor. É fundamental, pois, associar ao recurso do jogo um conjunto de estratégias que permita ao professor, como mediador do processo de ensino e aprendizagem, conduzir o aluno a construir sua própria solução e representá-la na forma de algoritmos.

As estratégias associadas são:

$1^{a}$ estratégia - Problematização, por meio de um problema contextualizado: A apresentação do problema como se fosse uma história, normalmente motiva o aluno, que se sente participante e comprometido com as regras para chegar à solução. Nesta etapa, o aluno pode realizar ações concretas - interagir com a máquina, e abstratas observar os resultados de suas ações, refletir sobre estes resultados e propor novas soluções, pois há um feedback imediato, permitindo ao usuário refletir sobre os erros e fazer novas tentativas. O aluno pode testar quantas soluções quiser, por um período mais ou menos razoável para a atividade, determinado pelo professor. Há, pois, amplo espaço para testar hipóteses e para a experimentação. Quando o aluno não consegue resolver o problema, é apresentada uma tela com convite para novas tentativas e, quando o aluno alcança o objetivo proposto, é apresentada uma tela de cumprimentos, com a solução final. Assim, por detrás do aparente "jogar" observa-se o processo de interação, descrito por Piaget (1983) entre o sujeito e o objeto (o próprio problema), onde o sujeito adapta suas ações de acordo com a resposta observada no objeto.

$2^{a}$ estratégia - Representação lógica e construção de hipóteses: Tendo vencido o jogo (ou solucionado o problema) o professor solicita que cada aluno escreva a sua solução, ou seja, a sequiência de interações que levaram à vitória. É importante destacar que a linguagem (forma) utilizada pelo aluno é totalmente livre. Nas primeiras tentativas, aproxima-se bastante de uma solução em linguagem natural, mas à medida que novos jogos são apresentados, a tendência do aluno é procurar uma forma mais sintética e rápida de fazer estes registros. Observe-se que registrar uma sequiência de ações é, em última instância, escrever um conjunto de passos que leva a um algoritmo, ou ainda, a formalização de um modelo.

$3^{\text {a }}$ estratégia - parte-se agora para a leitura e teste dos modelos, por meio de uma decodificação das representações, testando sua clareza e viabilidade de execução, ou seja, sua lógica. Nesta etapa, solicita-se que os alunos troquem entre si as anotações com os registros feitos na etapa anterior, de modo que cada aluno execute no computador aquilo que outro colega escreveu. O objetivo é, inicialmente, verificar se 
cada aluno conseguiu escrever algo que um outro colega entenda e, por sua vez, se o aluno consegue entender a representação construída por um outro (e estará, portanto, lendo um algoritmo). A seguir a seqüência é executada em um teste de mesa ou chinês, verificando se é adequada, por meio da experimentação.

$4^{\mathrm{a}}$ estratégia - cooperação para a construção coletiva de uma solução. Após a fase das soluções individuais, o objetivo agora é buscar uma solução que seja de consenso da turma, com a mediação do professor. Após muitas interações entre os alunos, é registrado no quadro a solução para o jogo. Nesse momento, o grupo tende a perceber que a linguagem utilizada deve ser tal que o todo o grupo entenda e que a seqüência de passos deve ser clara, sem ambigüidades. Essa fase permite chegar a uma representação de pseudo-código criada pelo próprio grupo.

$5^{\text {a }}$ estratégia - Como conclusão, o desafio final é construir uma representação na forma de algoritmo. Nessa etapa, o aluno precisa fazer com que a sua solução registrada em papel seja entendida e executada pelo computador. A turma é alertada para a necessidade de um outro nível de abstração, que é a tradução do algoritmo para uma linguagem de programação.

Agora, os jogos em si já não são mais o objeto de trabalho, mas podem ser utilizados para orientar, por exemplo, o enunciado do que deve ser programado.

Aproveita-se também a oportunidade para tratar de outros temas do ensino de computação, chamando a atenção dos alunos para a interface dos jogos, princípios de usabilidade, alfabetização visual e interatividade, elementos importantes para tornar mais eficiente e agradável a sua utilização pelos usuários.

Portanto, além da finalidade de entretenimento, observa-se que os jogos são elaborados de acordo com problemas envolvendo lógica, de forma que podem ser utilizados como ferramentas pedagógicas na fase inicial de ensino de algoritmos. Seu valor está nos aspectos motivacionais, no contato com a tecnologia, representação e experimentação de hipóteses, feedback imediato, entre outros. Por meio de um jogo o aluno consegue abstrair a lógica de um problema de forma mais simbólica e visualizar as seqüências lógicas necessárias para a sua resolução.

\section{4- Um exemplo: $O$ jogo MAGU, como uma tática de estratégias pedagógicas}

O jogo MAGU foi desenvolvido por um grupo de alunas do Curso de Especialização em Informática na Educação (ESPIE/UFRGS), na disciplina Tópicos de estratégias pedagógicas cognitivas e afetivas em ambientes computacionais de aprendizagem, em parceria com a disciplina Courseware.

Buscou-se, no pensamento de Piaget, subsidiar o jogo como estratégia cognitiva e afetiva quanto ao aspecto da interação entre sujeito e o objeto, para a construção do conhecimento; interação, no sentido dialético ente o sujeito e objeto, em que o sujeito age no ambiente com autonomia, toma decisões e produz mudanças.

Como fundamento de uma concepção de Educação, entende-se que há pressupostos sócio-construtivistas no Jogo MAGU. A história está contextualizada nas interações dos sujeitos em que os participantes, a partir de seus repertórios e de seus sistemas motivacionais buscam alcançar seu objetivo maior: ganhar o jogo.

O MAGU está estruturado em duas partes: uma Estória, que apresenta personagens e situações que colaboram para o contexto do jogo; e um Conjunto de Regras - que são as normas a serem seguidas para chegar à resolução de um problema.

Apresentamos a seguir algumas telas do jogo. A mesma seqüência (contextualização, experimentação, tela-resultado - obtenção da solução x não obtenção da solução) pode ser utilizada para se desenvolver jogos em quantidade suficiente que permita ao professor de algoritmos aplicar as estratégias propostas na seção 3. 
Inicialmente, há uma contextualização. No caso, foi criada a situação de um mago, MaGu (mago Magu) (Figura 2), que buscará auxiliar um personagem a resolver uma situação-problema correspondente ao enunciado proposto na Figura 1. Uma idéia é indivudualizar o personagem: se este estiver inserido em um repositório de jogos, por exemplo, o aluno-usuário poderia escolher um avatar para caracterizar o personagem.

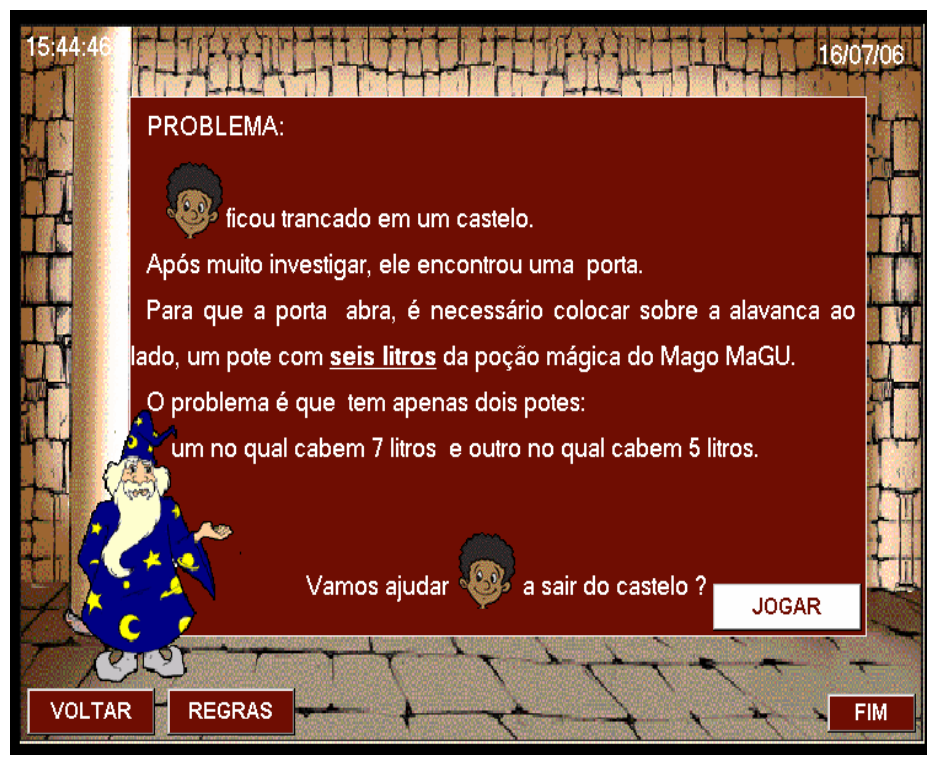

Figura 2: A contextualização

A Figura 2 mostra as possibilidades de navegação através dos botões: Voltar a uma tela inicial ou consultar as Regras (Figura 3) do jogo. O botão Jogar executa o jogo, permitindo a interação do aluno com o jogo.

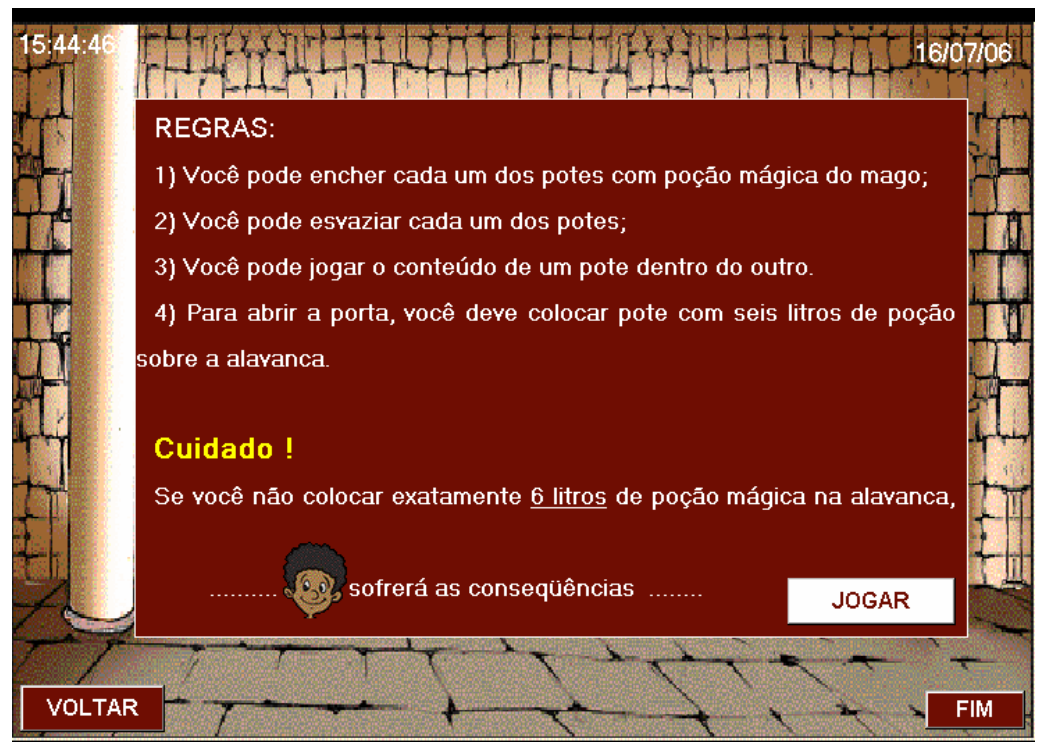

Figura 3: Regras do Jogo

A Figura 4 mostra a tela do jogo em si, e o botão para testar ou validar a ação, que será analisada logicamente, e o resultado será a apresentação de uma tela de 
congratulações pela Obtenção da Solução ou uma tela com incentivo para não desistir no caso da Não Obtenção da Solução. É preciso, pois, controlar a seqüência de navegação a partir de eventos que variam de acordo com as jogadas do aluno. Há um help acessível através de um ícone - um ponto de interrogação- comum a todas as telas Principal, para obter ajuda (dicas) sobre as regras, e m botão Fim, para finalizar.

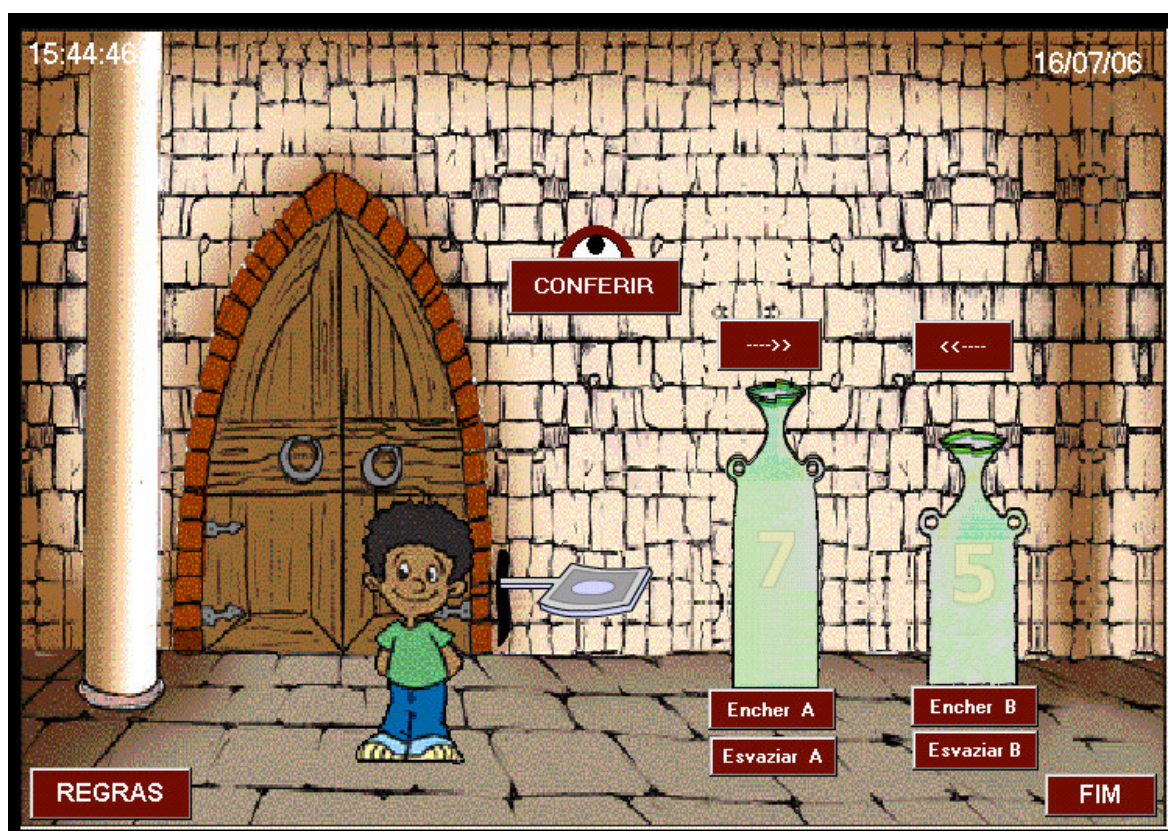

Figura 4: O Jogo em si

Durante o jogo, o aluno pode observar concretamente suas ações (encher e esvaziar os vasos), e seus resultados (completou o volume, sobrou, faltou), além de criar-se a expectativa do resultado ("agora vai dar", "e se eu fizer assim", etc). Assim, todas as etapas instigam ao levantamento de hipóteses e a sua testagem. Para Piaget é a partir da reflexão sobre o erro que se constrói a compreensão. O jogo MAGU, como tática para mobilização de estratégias afetivas e cognitivas, cria situações que desafiam o raciocínio do aluno. As tentativas de acertos no jogo provocam um desequilíbrio cognitivo que levam a reequilibrações sucessivas, e propiciam o estímulo às explorações e descobertas, importantes para a construção e reconstrução do conhecimento.

O feedback não se apresenta como "você acertou" ou "você errou", mas como uma solução alcançada ou a necessidade de nova tentativa, buscando respeitar a autoestima do aluno-usuário.

Exemplificando o início de uma seqüência lógica obtida por meio do jogo, segue-se um exemplo de descrição em linguagem natural, que pode ser feita por um aluno na solução do problema inserido no jogo:

Encher vaso $7 \mathrm{~L}$; transferir conteúdo para vaso $5 \mathrm{~L}$; esvaziar vaso $7 \mathrm{~L}$, jogando fora líquido que sobrou.

Esta seqüência também pode ser descrita assim, já com mais formalização do que o texto livre em linguagem natural anterior:

Estado inicial $V 7=0, V 3=0$; Passo $1-V 7=7, V 5=0$ [ação feita foi encher o vaso de 7 litros]; Passo 2 - V5 <- V7, ficando $V 7=2$, V5=5; [ação feita foi encher o vaso de 5 litros a partir do vaso de 7 litros; é apontada ação e mudança sobre o estado dos vasos] Passo $4-V 7<-0, V 5=5$ [ação feita foi esvaziar o vaso de 7 litros, indicando que o mesmo ficou com 0 litros] 
Observa-se que a linguagem natural descrita é uma expressão do pensamento. "O pensamento dirigido é consciente, isto é, persegue objetivos que estão presentes na mente daquele que pensa. (...) e pode ser comunicado por meio da linguagem". (Piaget, in Vygotsky, 1998, p.14)

O jogo, como discutido aqui, mostra o seu valor educacional, já que é possível utilizá-lo como meio de desenvolver o raciocínio lógico. No entanto, a atuação do professor como mediador, guiando o grupo na sequiência de estratégias propostas na seção 3, é fundamental. Senão, os jogos serão mero divertimento já que são muito simples de forma a permitir fácil representação da solução.

\section{5- Considerações Finais}

Um dos aspectos fundamentais na utilização dos jogos é o fator motivador, podendo-se destacar sua importância relacionado ao objetivo educacional. Convém lembrar que os jogos propostos têm como objetivo desenvolver o raciocínio lógico indispensável a construção de algoritmos e programação.

É importante que os jogos desenvolvidos sejam atrativos e, portanto, que possuam determinadas características, citadas por Tarouco (2005), possuir regras (as regras do jogo), metas (o objetivo é ganhar o jogo resolvendo o problema), ser interativos (o aluno executa ações), produzir resultados (desenvolvem o raciocínio lógico) e ser divertidos (possuem animação e são atrativos). Tais elementos são fundamentais para que os jogos se configurem como ferramentas educacionais para o processo de ensino-aprendizagem de algoritmos e programação.

Talvez, no entanto, os dois aspectos mais relevantes a destacar sejam: i) o fato dos alunos poderem perceber a importância de uma linguagem clara para representação da solução de forma que permita a qualquer pessoa jogar utilizando aquela seqüência; ii) o fato do aluno poder verificar a funcionalidade da solução proposta através da experimentação - essa abordagem permite ao professor outra forma de trabalhar o erro.

Entendemos que os jogos eletrônicos são inovadores e podem ser usados como táticas nas estratégias pedagógicas. Observa-se no jogo que as ações perpassam pela percepção, linguagem e pelo pensamento que operam na construção de conhecimento.

\section{Referências}

BORGES, M. A. F. Avaliação de uma Metodologia Alternativa para a Aprendizagem de Programação. VIII Workshop de Educação em Computação - WEI 2000. Curitiba, PR, 2002.

FAYARD, P., O jogo da interação: informação e comunicação em estratégia. Caxias do Sul: EDUCS, 2000.

JOHNSON, S. Surpreendente!: a televisão e o videogame nos tornam mais inteligentes. Rio de Janeiro: Elsevier. 2005.

MENDES, A. J. N. Software educativo para apoio à aprendizagem de programação, VIII Taller Internacional de Software Educativo- TISE, Santiago, Chile, 2002.

PEREIRA JR, J. C. R., RAPKIEWICZ, C. E.. O Processo de Ensino e Aprendizagem de Algoritmos e Programação: Uma Visão Crítica da Literatura. WEIMIG - Workshop de Educação em Informática de Minas Gerais. BeloHorizonte. 2004.

PIAGET, J. A epistemologia genética: sabedoria e ilusões da filosofia, problemas de psicologia genética. São Paulo, Abril Cultural. 1983.

RODRIGUES JUNIOR, M. C. Como Ensinar Programação? Informática - Boletim Informativo Ano $\mathrm{I}^{\circ}$ 01, ULBRA, Canoas, RS, 2002.

SILVEIRA, S.R. Estudo e Construção de uma ferramenta de autoria multimídia para elaboração de jogos educativos. Dissertação Mestrado POA/PPGC/UFRGS 1998. 
TAROUCO, L. M. R., ROLAND, L. C., FABRE , M. C. J. M., KONRATH, M. L. P. Jogos educacionais , RENOTE -Novas Tecnologias na Educação, v. 2, n. 1. 2004.

TAROUCO, L. Jogos educativos via WWW, Disponível em: http://penta3.ufrgs.br/animacoes/JogosEducacionais/ Acesso: 25 de nov 2005.

VYGOTSKY, L.S. Pensamento e Linguagem. São Paulo: Martins Fontes, 1998.

YOURDON, Edward. Análise Estruturada Moderna. Rio de Janeiro:Campus, 1990. 